\title{
Sciendo
}

\section{Value management in Blockchain technology related projects}

\author{
KAI CHEN \\ Babes-Bolyai University, Cluj-Napoca, Romania \\ Kane201086@hotmail.com
}

PICBE | 194

\begin{abstract}
Because of the development of Bitcoin in recent years, the foundational technology behind it, the Blockchain technology, also begins to attract attention from international banks and companies, and entrepreneurs have developed Blockchain technology related projects not only in financial industries but also other industries. In this dynamic information economic environment nowadays, high-tech economic projects based on Blockchain are very important, and when it comes to the value management more factors have to consider. The research of value management is a longterm subject that brings benefits to projects and the analysis with Blockchain projects is very helpful for start-ups, entrepreneurs as well as stakeholders. The purpose of this study is to analyze the relationship between Blockchain technology projects and value management, and find better ways of value management in Blockchain projects.
\end{abstract}

Keywords: value management, Blockchain projects, decentralized autonomous organizations, value added

\section{Introduction}

With the appearance and development of Bitcoin since 2009, the Blockchain technology has become so compelling that almost all the international banks and companies pay attention to it and begin the research and development of it, and the application of Blockchain in different industries especially in finance shows a good future, which has been approved by some projects. The famous Blockchain projects in financial industries, such as R3 CYE, China Ledger, are telling the world there is a revolution in financial industry and present ecosystem. No one should ignore the obvious improvement in banks and financial system. What's more, the Blockchain technology related projects have extended to other industries, such as education, marketing, arts.

The analysis of Blockchain projects in the view of value management can provide better management strategies. Compared to the internet that shares merely information, Blockchain technology is focus more on the value transaction and data recording with its features: decentralization, distribution and trustless, transparency and safety, automation, which make it develop fast and already achieved some goals in financial area. The most special and important feature of Blockchain projects is the decentralization. Blockchain technology can effectively help to improve the efficiency, decrease the operation costs, adapt to market needs flexibly, avoid manipulation and fabrication in certificates, and reduce potential risks. The new decentralized autonomous organization (DAO) is a popular management structure in Blockchain projects.

In this paper, in order to have a better understanding of value concept from agricultural society to industrial economy, then to the nowadays informational economy, the development of value concept will be demonstrated in a historical context. Several 
important factors in value management will be discussed in the context of Blockchain projects, including the value chain management, budget management, performance evaluation, and incentive mechanism and facilitator competences. Selected Blockchain projects will be used as research cases for a clear understanding of the change and new requests for value management. Based on the research, suggestions and limitations are given for a further research.

\section{Literature review}

\section{Value transition in modern society}

The value in nowadays is more important in value exchange and sharing. In the present market, the economy depends more on information and technology compared to the industrial economy and capitalism economy. Porat, (1977) describs 'information economy' as an economy in which production is associated with knowledge, communication and information. Value is created by more diverse factors and labor becomes more difficult used to measure the value rather new technology places challenges for value management.

The concepts of value are always in a dynamic developing situation, in flexible environments no matter in past decades or nowadays. Smith. A (1776) mentioned in his book The Wealth of Nations that early theories associated value with an economic dimension, specifically value as a single entity in time and an output of labor. A key point for Smith's comprehension for value is the division of labor. Ricardo. David (1817) is critical of Adam Smith's 'adding-up theory' of value and shows his different understanding of value in his book The Principles of Political Economy and Taxation that value is indeed determined by their scarcity relative to the demand for them. Jevon (1871) develops the marginal utility theory which refers to the satisfaction that an individual gains from the consumption of an additional unit of a particular good in a given context (King \&Mclure, 2014). This theory dismisses any material embodiments of value and over-emphasizes the efficacy of free markets in coordinating any sort of meaningful action in societies, based on generalized assumptions, such as utility-maximization and equilibrium (Pazaitis et al 2017). According to Karl Marx's labor theory of value, value is essentially a social, objective and historically relative category; it is social because it is determined by the overall result of the fluctuating efforts of each individual producer. At present, Allee (2000) put forward that value is identified as the return of a fair price or exchange by recipients for the benefits received from goods, services or knowledge that are deemed desirable or useful in both tangible and intangible forms. We can find that the factors influencing value concepts are increasing and the relationships between value and variables is more complicated. Considering value management, the clear understanding of the value in Blockchain projects in information economy is the first and fundamental step.

Table 1. The value transition from the industrial economy to the information economy

\begin{tabular}{|l|l|l|}
\hline & Industrial economy & Information economy \\
\hline Production of value & $\begin{array}{l}\text { Division of labor } \\
\text { Exchange value }\end{array}$ & $\begin{array}{l}\text { Communities of users and } \\
\text { producers }\end{array}$ \\
\hline
\end{tabular}




\begin{tabular}{|l|l|l|}
\hline & Production for surplus & $\begin{array}{l}\text { Use value } \\
\text { Production for sharing }\end{array}$ \\
\hline Record of value & $\begin{array}{l}\text { Double-entry bookkeeping } \\
\text { Rationalization and } \\
\text { depersonalization } \\
\text { Quantification and abstraction }\end{array}$ & $\begin{array}{l}\text { Blockchain } \\
\text { Decentralized consensus and } \\
\text { engagement } \\
\text { Variety and polycentricism }\end{array}$ \\
\hline \multirow{2}{*}{ Actualization of value } & Commodities in markets & $\begin{array}{l}\text { Commons in market } \\
\text { Money }\end{array}$ \\
& Utility maximizalion tokens \\
& & Perceived social benefit \\
\hline
\end{tabular}

PICBE | 196

Source: adapted from Pazaitis, Filippi, Kostakis (2017).

We can find from the change of the value in industry economy and information economy that the Blockchain technology rationalizes the further development of value creation and maximum of value, at the same time incentives people to make meaningful contributions economy development. Managers and workers are willing to share their creative energy, ideas, social relationships and other resources. Productive Blockchain project can create more intangible value that is managed and utilized according to the settled rules in the project.

In the part of record of value, with the Blockchain technology which is a decentralized record of value with the ability to encapsulate qualitatively different data, the management is much more effective than earlier. And the Proof of Value (PoV) protocol offers a mechanism for the establishment of consensus that determines the value concept in different projects faster. Participants of different projects can understand and work hard for the common goal. Thus the value management can systematizes the common value concept that is attached to meaningful collaboration. The value is developed to the degree of the governance of social relations.

In actualization of value, the popular use of tokens helps to ask more participants contribute to projects and they can benefit from a collaborative process. The digital tokens are a generic and measurable unit of value issued by Blockchain technology applied projects with security protocol and instruction for use. With those rules, value transfer become more convenient, efficient and safe, and participants in projects can contribute and share their resources with more initiative and benefits from each other. What's more, the utilization and management of tokens also bring benefits to the products and services in the decentralized autonomous projects in different industries. So the value management has moved its focus from maximum value in products and services to the safety of digital tokens and social benefits.

\section{Key factors in value management}

The value management is to identify the functions of a project, product, or service with recognized techniques and providing the necessary functions to meet the required performance at the lowest overall cost (SAVE International 2001). With advanced technology development, value management is facing more challenges in current practice information economy. With different size, subject and complexity of projects, the research of value management is continually developing. Value in contemporary project 
management has shifted from ideas of 'value management' to ideas of 'understanding how stakeholders value different things' (Oliomogbe \& Smith, 2013). There are more aspects we have to consider for a comprehensive and profound understanding of the developing role of value management in Blockchain technology based projects.

\section{Value chain management}

PICBE | 197

The value chain management is the process of organizing the connected group of activities that create value by producing goods or services from basic raw materials for purchase by a consumer. The basic objectives of employing value chain management in a business is to integrate communication and increase cooperation between production chain members in order to decrease delivery times, reduce inventories and increase customer satisfaction (BusinessDictionary., n.d.).

Good utilization of value chain management is able to help the customers optimize their business activities along the supply chain continuum through adoption of Lean principles throughout the supply chain. This has generated multiple benefits including elimination of waste, reduction in redundancy, productivity gains and other positive outcomes.

Most Blockchain projects are decentralized autonomous organizations which the role of managers is not so important or strong in traditional projects. People attend in the Blockchain projects are employees working for the project development as well as the managers to decide the development direction. Take the project Imbrex as example, which is a real estate platform where all the owners and buyers of houses and apartment can share their information on it. Compared to the traditional real estate agency, this decentralized platform has more suppliers of house and apartment, and the cost to maintain suppliers is much lower even little. The suppliers at the same time are managers of this platform as they can use their tokens to decide new rules and regulations which are beneficial to themselves.

\section{Budget management}

Budget management is the analysis, organization and oversight of costs and expenditures for a business or organization. Managing a budget requires adhering to strict internal protocols on expenditures. A well-managed budget allows for continued smooth operations and growth.

A typical budget allocates funds for payroll, general expenses, equipment, services, taxes and miscellaneous expenditures. Careful decisions have to be made regarding the amount of money spent each month on specific items (Reference, n.d.).

Although Blockchain projects have different characteristics than the traditional ones, they still need to have overall budget allocating payroll, general expenses, services and advertisement. However, this management can be done more efficiently as all participants can take part in budget management as they work consciously for common goal.

\section{Performance evaluation}

Performance evaluation is the process of creating a work environment in which people 
are enabled to perform to the best of their abilities (Heathfield, 2018). Numeric ratings are the tool always used in evaluation in order to have a clear rating according to employee's performance. The result is concise, understandable, objective and universal.

These are several goals of an effective evaluation process.

First, the contribution from projects members can be embodied in a comprehensive and reasonable evaluation system. More important is that the career development of employees' is considered and the evaluation provides opportunities to realize it in a detailed schedule.

Second, the performance evaluation can help not only projects employees but also managers to have a quite clear understanding of the requirements of the projects and performance. The accurate goal setting, performance feedback, and documentation can be used to ensure members understand their required outputs.

Third, the performance evaluation provides evidence of non-discriminatory promotion, pay, and recognition processes (Heathfield, 2018). It is beneficial to solve the problems that are easy to be ignored in work such as racial and gender discrimination, distribution of bonus for a project team.

In Blockchainprojects, the performance evaluation is processed by the new consensus protocol Proof of Value (PoV). It consists of a peer-to-peer evaluation system and a reputation system. The peer-to-peer evaluation system is used to determine the perceived value of the various contributions and the reputation system can determine the rights in a project with one's contributed value contributed (Davidson et al., 2016). All the data can be recorded safely in Blockchain to ensure the transparent and open advantage of the projects. The managers are not the main rulers in evaluation design but all members can participate in the evaluation system and supervise it.

\section{Incentive mechanism}

The incentive mechanism is designed with incentive rules and work environment to incentive, guide, maintain as well as regulate the workers' performance together with an effective communication and information system. The purpose of this mechanism is to lead workers to have the maximum subjective initiative and creativity. As the human beings are the core of value creation, the effective incentive mechanism can arouse the enthusiasm of managers and workers to create better value for projects.

With the characteristic of being decentralized and trustless in Blockchain technology, Bitcoin is the first concrete example of a distributed network with an intrinsic incentive mechanism (Van Valkenburgh et al., 2014). Every member in project is simultaneously a contributor, an actual shareholder as well as a manager in different services and activities. Hence, everyone has an incentive to maximize the value of and from that project and this is a progress of value management as it transformed the passive incentive to initiative incentive.

\section{Blockchain technology and Blockchain projects}

Bitcoin marked the beginning of a nascent industry of distributed applications with the issuance of tokens with Blockchain technology (Van Valkenburgh et al., 2014). Blockchain is a decentralized and distributed digital ledger that is used to record all transactions 
across which are almost impossible to be manipulated (Amstrong, 2016). Blockchain has the characteristics of decentralization, being trustless, safety, transparency, and automation. The goal for Blockchain is to make the decentralization autonomous organization management come true. The inspiration of decentralized autonomous organization comes from the indirect coordination in certain species of animals (such as ants, termites and birds) (Marsh et al., 2007). And the characteristic of decentralization makes Blockchain technology appealing in this information economy. Projects build on Blockchain technology to replicate the same model of the animals in a spontaneous and safe network. With the advanced characteristics of decentralization, distribute, trustless, safety, Blockchain technology makes it possible for people to effectively manage, coordinate and reward contributions, while they collectively develop and deploy projects.

According to Swan (2015), Blockchain 3.0 is Blockchain applications beyond currency, finance, and markets-particularly in the areas of government, health, science, literacy, culture and art. Most of the present Blockchain projects are belonging to public Blockchain type, which means they are open-source platform and anyone can access to the data in the projects without any limitation. The benefits include that all the data are recorded safely in Blockchain with little possibility of manipulation. Around the world, hundreds of thousands of technologists and developers are working to build applications and platforms that will bring the potential of Blockchain technology to fruition. Although the Blockchain ecosystem will take time to fully develop and enmesh with economies-atlarge, there are already many organizations deliver applications that interact with Blockchain to create new modes of creating, exchanging value and value added.

The tendency of decentralized projectsbased on Blockchainis evolving models in market segments as far-reaching as finance, music, gaming, and social media with remarkable results, and is pushing the Blockchain industry forward towards an era which is less about speculation and more about results, adoption, and making a substantive improvement in the lives of users.

Take District0x as an example, it is a public Blockchain application and is a network of decentralized markets and communities. The Functions of this project include 1. Posting \& listing 2. Search and filtering 3, Ranking \&reputation 4. Payments \& invoicing. Users can buy tokens-district0x Network Token which is used to provide all internet citizens with an opportunity to freely join and contribute to any district, to align incentives across all of a district's participants, and to implement coordinated decision-making mechanisms to the district0x Network. With tokens, users can use the functions with a stack of Ethereum smart contracts and front-end libraries distributed on InterPlanetary File System (IPFS) which power a district's basic functionalities. Smart contract is very important for Blockchain and also helps DAOs to develop new projects inside the virtual chain e.g. building new products, developing hardware or writing code (Jentzsch, 2017). Thanks to Blockchain technology, all the data is recorded and managed by Aragon which is a revolutionary new platform for the deployment of unstoppable virtual organizations and entities.

\section{Methodology}

For this article, the following methods have been employed: 
Descriptive research methods, through the collection of a series of data on Blockchain projects and value management, which are tabulate, depict and describe, and which will be accompanied by tables and figures, in order to gain a better understanding of the variation in value management on Blockchain projects.

Comparative research methods, which allows for a systematic comparison of the value management in traditional project and Blockchain projects considering the explicit value concept, value driven factors, value based management in whole process, and value concept communication between managers and employees. The advantage of Comparative research is the fact that it allows for the analysis of a small number of variables, given a scarcity of data (Collier, 1993).

Historical research methods, in order to have a better understanding of the value concept in historical context from an evolutionary perspective and the Blockchain technology application development, this research method will offer a needed insight into the origin of Blockchain technology from the Bitcoin, with a highlight on the recent years, which is the whiteness of the greatest and fastest development of Blockchain.

Case study method, this method is implemented through research and development of Blockchainin some selected projects. With careful reading and study of Blockchainprojects the factors of management in Blockchain projects is appropriate to research.

Inductive research methods, which allow for the drawing of conclusions about the advantages and disadvantages of Blockchainprojects from the specific observations derived from the data and through the case study. From the conclusion we can also have a further prospect for the value management in Blockchain projects.

\section{Results and discussions}

The comprehensive and precise value concept of a Blockchain project is the very beginning and foundation of successful value management. No matter in traditional projects or Blockchain projects, good preparation and understanding of the value concept are important to manage a successful project. Norton and McElligot (1995) have stressed the importance of the accurate understanding and introduction related information about the project is crucial to the success of projects. In Blockchain projects, more than the typical and fundamental information of project management and value management such as project specifications, cost data, and project constraints, should be collected and assimilated, multidisciplinary composition is another vital factor deciding the efficiency and even result of project (Kelly et al., 1993).

In traditional project management, professional experience, knowledge, and personalities are main requirements associated with managers. Although if every member can understand some value management knowledge, which is beneficial to the management, the reality is that only managers are required to have the knowledge and experience. This situation is different in Blockchain projects as every member in a Blockchain project is opener to new and advanced knowledge, experience, as well as value management issues, and simultaneous to make contribution to the value of the project.

In traditional project management, the role of managers is very crucial to the result 
of a project, as they control and lead a team to reach the objectives (SAVE International 2001). A qualified project manager should have comprehensive knowledge and experience in planning, decision-making, interpersonal communication, time management, lateral thinking and so on. So it always seems that the success of a project is the responsibility of managers. While in Blockchain projects, all the participants can be manager and it is very effective to make full use of the strong competence from every member. It is not important of the academic and work background of a participant, because everyone is simultaneous to make contribution to the value production to realize a common goal with creative ideas and personal resources.

In value management, Blockchainprojects are different from the traditional projects when people focus on the value. First, the value sharing is more efficient and the scale of value sharing becomes bigger and stakeholders are more. Second, the performance evaluation and incentive mechanism have a big change. As the roles of managers and employees are mixed into one, the performance evaluation is adjusted accordingly. And the proof of work and proof of value play important roles in incentive mechanism.

In value management there are four main procedures. And in the Blockchain projects, the 4 aspects are influenced by this innovative technology. The 4 aspects are: to have an explicit value concept, to clear the value-driven factors in certain projects, to implement value-based management in the whole process of operation, to implement the value communication between managers and employees

Table 2. The comparison between the value management in traditional projects and in Blockchain projects

\begin{tabular}{|c|c|c|}
\hline & Traditional projects & Blockchain based projects \\
\hline $\begin{array}{l}\text { To have an } \\
\text { explicit value } \\
\text { concept }\end{array}$ & $\begin{array}{l}\text { This is the first and significant step } \\
\text { for value management, and } \\
\text { managers need to make an explicit } \\
\text { value concept of the project, which } \\
\text { are the rules for the following } \\
\text { performance. It is related to the } \\
\text { project mission, cooperated } \\
\text { industries, strategies } \\
\text { performance guidance. } \\
\text { Traditional projects ask managers to } \\
\text { ensure all the members of that } \\
\text { project understand the goal } \\
\text { explicitly, which requests the } \\
\text { managers have a comprehensive } \\
\text { understanding and clear } \\
\text { explanation, and the members are } \\
\text { better to have knowledge of the } \\
\text { value management. In most cases, } \\
\text { some members do not understand }\end{array}$ & $\begin{array}{l}\text { As the Blockchain projects are } \\
\text { decentralized autonomous } \\
\text { organization where all the participants } \\
\text { are clear with the mission, vision and } \\
\text { value concept of that project and } \\
\text { members' initiative is stronger than } \\
\text { traditional ones. The role of managers } \\
\text { is replaced by participants themselves, } \\
\text { so the time and work to make sure all } \\
\text { employees understand the value } \\
\text { concept can be saved. The result is that } \\
\text { all the participants are clear of the } \\
\text { value concept before they start in the } \\
\text { project rather than after the projects } \\
\text { begin. }\end{array}$ \\
\hline
\end{tabular}




\begin{tabular}{|c|c|c|}
\hline & $\begin{array}{l}\text { the value concept of the project, and } \\
\text { the result is they cannot have a } \\
\text { spontaneous performance. }\end{array}$ & \\
\hline $\begin{array}{l}\text { To clear the } \\
\text { value-driven } \\
\text { factors in certain } \\
\text { projects }\end{array}$ & $\begin{array}{l}\text { The value-driven factors are } \\
\text { innovative and strategic activities } \\
\text { that help to realized value creation } \\
\text { and value added. They are the } \\
\text { detailed practice creating the } \\
\text { maximum value and transform the } \\
\text { value concept into value-driven } \\
\text { incentive. This part in traditional } \\
\text { projects again needs lots of work } \\
\text { from managers who make sure } \\
\text { employees can work efficiently. The } \\
\text { challenge includes the various and } \\
\text { effective activities should be } \\
\text { implemented to ensure the value } \\
\text { creation and value added. }\end{array}$ & $\begin{array}{l}\text { The advantage of Blockchain projects is } \\
\text { that all the participants are clear about } \\
\text { the value concept in their project and } \\
\text { they are using all the innovative and } \\
\text { strategic activities to achieve the goal } \\
\text { as the project is an open-resource } \\
\text { platform where participants can } \\
\text { contribute any ideas and activities. } \\
\text { Once an idea is welcomed by most } \\
\text { participants, it can promote the project } \\
\text { development and value management. }\end{array}$ \\
\hline $\begin{array}{l}\text { To implement } \\
\text { value-based } \\
\text { management in } \\
\text { the whole } \\
\text { process of } \\
\text { operation }\end{array}$ & $\begin{array}{l}\text { This is the key of value management } \\
\text { as the goal of this management is to } \\
\text { maximize value in materials as well } \\
\text { as in intangible value, and to have a } \\
\text { sustainable value creation. In this } \\
\text { situation, the value management is a } \\
\text { long-term work requiring all } \\
\text { members in projects focus on the } \\
\text { value creation in the whole process. } \\
\text { With the process of project, the } \\
\text { value-based management may } \\
\text { influenced by various unknown } \\
\text { reasons. Or the original goals are } \\
\text { changed. Managers need to enhance } \\
\text { the original value in the whole } \\
\text { process but adjust to the sudden and } \\
\text { uncertain factors, such as the } \\
\text { working duration. }\end{array}$ & $\begin{array}{l}\text { This point is also the advantage of } \\
\text { Blockchain projects as they are } \\
\text { decentralized autonomous } \\
\text { organization. The characteristic of } \\
\text { being decentralized makes value } \\
\text { management is concerned by the } \\
\text { entire participants as the value is } \\
\text { created and added by them. And the } \\
\text { characteristic of being autonomous } \\
\text { means in the whole process every } \\
\text { decision and changes are caused by } \\
\text { participants without intervention from } \\
\text { managers. }\end{array}$ \\
\hline $\begin{array}{l}\text { To implement } \\
\text { the value } \\
\text { communication } \\
\text { between } \\
\text { managers and } \\
\text { employees }\end{array}$ & $\begin{array}{l}\text { It is the guarantee the god } \\
\text { communication between managers } \\
\text { and employees. The value } \\
\text { management requests managers } \\
\text { and employees have consensus of } \\
\text { the common goal of project. } \\
\text { In traditional projects, the } \\
\text { communication between managers }\end{array}$ & $\begin{array}{l}\text { In Blockchainprojects, the managers } \\
\text { are replaced or transformed to } \\
\text { participants. So the problem of } \\
\text { communication between these two } \\
\text { roles is not a big problem anymore. All } \\
\text { the communication issues are solved } \\
\text { by the smart contracts and other } \\
\text { software. }\end{array}$ \\
\hline
\end{tabular}




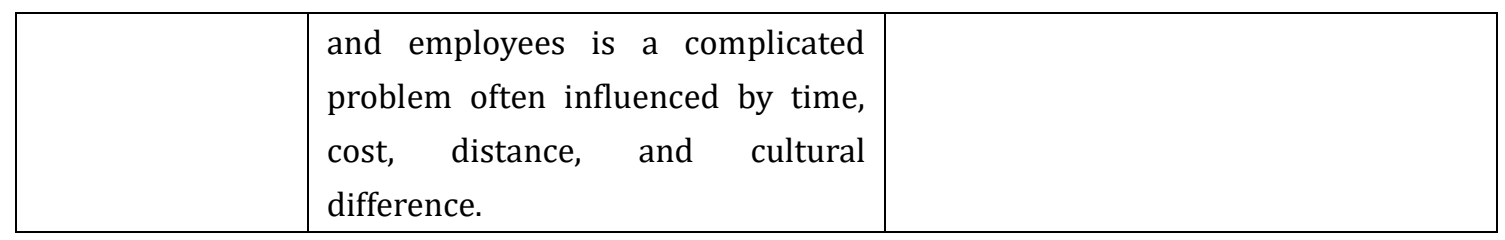

Source: Authors' own research.

PICBE | 203

In some Blockchain projects there existing some limitations. For the projects in order to build decentralized and self-organized communities, the development usually means formalizing into a more rigid hierarchical structure and adopting a marketoriented approach. Some projects start to turn into a company or other legal entity to accumulate necessary funds and reward contributors with economic returns. This approach often conflicts with the original intentions of the projects, which is generally focused towards building social relations and promoting cooperation among a distributed network of peers in various industries, rather than increasing profits.

\section{Conclusion}

The main motivation of this paper is to explore the value management in Blockchain related projects which are mostly belonging to decentralized autonomous organizations. The objective of study is to have a better understanding of the value management in Blockchain projects. In the most important procedures of value management including an explicit value concept, the value-driven factors in certain projects, value-based management in the whole process of operation, the value communication between managers and employees, if there are difference we should pay attention in order to have better management in the following work. And the main research question is what difference there are compared the value management in traditional projects to it in Blockchain projects. What are the advantages and limitations of Blockchain projects when it comes to value management. With the brief understanding of the evolution of value concepts in different economy types as well as the knowledge of the main parts of value management and Blockchain technology, it is helpful to analyze the Blockchain projects and other future Blockchain technology applications.

Theoretical understanding of value perception begins with historical concepts of value in the economic thought. The concepts for value have been evaluated since its birth and the corresponding value management is developing. In this information economy, the value concept is more focus on sharing and produced by digital tokens with Blockchain technology which is beneficial from the decentralization, transparency and data safety resulting in a better efficiency, effectiveness and participant's performance. The four main parts of value management--Value chain management, Budget management, performance evaluation, and incentive mechanism are included for the analysis. And details of difference in Blockchain projects are discussed in context.

Based on that research we conclude that value added has two different approaches, respectively:

First, the application perspective- by using the Blockchain technology and decentralized autonomous organization structure bring opportunities related to efficient 
communication, low costs with labor, higher efficiency in performance, information sharing, better quality

Second, the management perspective, which could add significant value to the business itself through the advantages in Blockchain projects- decentralization, safety, transparency and trustless.

Blockchain technology as a new and compelling topic has attracted more attention from people in various industries with its incredible features-decentralization, trustless, safety and automation, which is influencing the development of many industries in information economy in a new direction. As a recording medium, it could effectively improve the value management in related projects and be applied in more and more industries to help the autonomous operation of projects. Although Blockchain technology is not working as an artificial intelligence, it had the function in value management in reducing the cost in communication between participants and ensuring more people in less developed areas access to various industries. The utilization of Blockchain technology in value management can meet the key request to achieve value maximization and a more rational and efficient way for distributed resources.

However, the operation of Blockchain projects poses certain challenges to the internal relations, trust between participants, reciprocity and intrinsic motives (Pazaitis et al, 2017). The technology is still at an early stage and more empirical data are necessary to support its practical application for further evolution especially when it comes to the most significant value creation and management for companies. At the same time, as the technology yet has to reach a dominant and mature design, it is too early to predict how it would operate on large scale. Positively, the appearance and development of the application of Blockchain technology in various projects presents a promising scenario for the temporary economy and the possibility of the future.

\section{References}

Allee, V. (2000). The value evolution: addressing larger implications of an intellectual capital and intangibles perspective. Journal of Intellectual Capital, Vol. 1 Issue: 1, 17-32.

Armstrong, S. (2016). Move over Bitcoin, the Blockchain is only just getting started. Wired. Retrieved From https://www.wired.co.uk/article/unlock-theBlockchain

BusinessDictionary. (n.d.) Retrieved from http://www.businessdictionary.com/definition/value-chain-management.html

Collier, D. (1993). The comparative method, in Finifter A. (Ed) Political Science: the state of the discipline II. Retrieved from http://polisci.berkeley.edu/sites/default/files/people/u3827/APSATheComparativeMethod.pdf

Davidson, S., De Filippi, P., Potts, J., (2016). Economics of Blockchain. Retrieved from http://dx.doi.org/10.2139/ssrn.2744751.

Heathfield. S. M. (2018). Performance Management Here's Your Quick Start Learning Guide to Performance Management. Retrieved from 
https://www.thebalancecareers.com/performance-management-1918226

Heathfield. S. M. (2018). The 5 Goals of Employee Performance Evaluation. Retrieved from https://www.thebalancecareers.com/employee-performance-evaluationgoals-1918866

Jentzsch, C. (2017), Decentralized Autonomous Organization To Automate Governance, final draft, under review. Retrieved from

PICBE $\mid 205$

https://scholar.google.ro/scholar?q=decentralized+autonomous+organization+B lockchain\&hl=en\&as_sdt=0\&as_vis=1\&oi=scholart\&sa=X\&ved=0ahUKEwjE75e8z o3XAhWCwxQKHdg3D5kQgQMIKDAA

Kelly, J., and Male, S. (1993). Value management in design and construction: The economic management of projects. E \& FN Spon, London.

King. J \& Mclure. M, (2014), Economics history of the concept of value. Retrieved from http://www.business.uwa.edu.au/_data/assets/pdf_file/0004/2478883/14-06History-of-the-Concept-of-Value.pdf

Marsh, L., Onof, C. (2007). Stigmergic epistemology, stigmergic cognition. Cogn. Syst. Res. $9(1 / 2), 136-149$.

Norton, B. R., and McElligot, C. W. (1995). Value management in construction: A practical guide, Macmillan, Basingstoke, U.K.

Oliomogbe, G.O. \& Smith, N. J. (2013). Value in megaprojects, Organization, Technology \& Management in Construction. Retrieved from https://pdfs.semanticscholar.org/09d1/2143402a40aeda03f3e406c85cbfa23cfa 2d.pdf

Pazaitis.A, Filippi.P.D, Kostakis.V, (2017). Blockchain and value systems in the sharing economy: The illustrative case of Backfeed. Technological Forecasting \& Social Change 125 (2017) 105-115

Porat M. (1977). The Information Economy: Definition and Measurement. Office of Telecommunications (DOC), Washington, DC.

Reference (n.d.). What Is Budget Management? Retrieved December 16, 2018, from https://www.reference.com/business-finance/budget-managementced152ef1e5a6323

SAVE International. (2001). Value methodology standard. Retrieved from http://www.value-eng.org/manuals/vmstd.pdf.

Smith, A. (1776). The Wealth of Nations. An electronic classics series publication. Retrieved from https://eet.pixelonline.org/files/etranslation/original/The\%20Wealth\%20of\%20Nations.pdf

Swan. M. (2015). Blockchain Blueprint for A New Economy. O’Reilly Media.

Van Valkenburgh, P., Dietz, J., De Filippi, P., Shabad, H., Xethalis, G., Bollier, D. (2014). Distributed Collaborative Organisations: Distributed Networks \& Regulatory Frameworks. Coin Center. 